\title{
Article
}

\section{Integration of professional judgement and decision-making in high-level adventure sports coaching practice}

\author{
Collins, L., and Collins, D.
}

Available at http://clok.uclan.ac.uk/12227/

Collins, L., ORCID: 0000-0002-7478-1140 and Collins, D. ORCID: 0000-00027601-0454 (2015) Integration of professional judgement and decision-making in high-level adventure sports coaching practice. Journal of Sports Sciences, 33 (6). pp. 622-633. ISSN 0264-0414

It is advisable to refer to the publisher's version if you intend to cite from the work. http://dx.doi.org/10.1080/02640414.2014.953980

For more information about UCLan's research in this area go to http://www.uclan.ac.uk/researchgroups/ and search for <name of research Group>.

For information about Research generally at UCLan please go to http://www.uclan.ac.uk/research/

All outputs in CLoK are protected by Intellectual Property Rights law, including Copyright law. Copyright, IPR and Moral Rights for the works on this site are retained by the individual authors and/or other copyright owners. Terms and conditions for use of this material are defined in the policies page.

\section{CLoK}

Central Lancashire online Knowledge www.clok.uclan.ac.uk

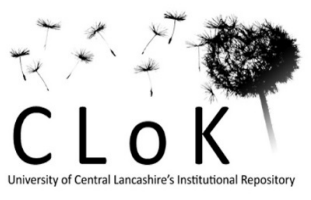


This is a pre-proof corrected manuscript, as accepted for publication, of an article published by Taylor \& Francis in Journal of Sports Sciences on $14^{\text {th }}$ November 2014, available online: http://www.tandfonline.com/doi/abs/10.1080/02640414.2014.953980

Integration of professional judgement and decision-making in high-level adventure sports coaching practice

Loel Collins \& Dave Collins

Institute of Coaching and Performance, University of Central Lancashire, Preston, UK 


\begin{abstract}
This study examined the integration of professional judgement and decision-making processes in adventure sports coaching. The study utilised a thematic analysis approach to investigate the decision-making practices of a sample of high-level adventure sports coaches over a series of sessions. Results revealed that, in order to make judgements and decisions in practice, expert coaches employ a range of practical and pedagogic management strategies to create and opportunistically use time for decision-making. These approaches include span of control and time management strategies to facilitate the decision-making process regarding risk management, venue selection, aims, objectives, session content, and differentiation of the coaching process. The implication for coaches, coach education, and accreditation is the recognition and training of the approaches that "create time" for the judgements in practice, namely "creating space to think". The paper concludes by offering a template for a more expertise-focused progression in adventure sports coaching.
\end{abstract}

Keywords: adventure sport, coaching, judgement, individualisation, decision-making 
Professional judgement and decision-making (PJDM; Abraham \& Collins, 2011; Martindale \& Collins, 2010) act to synergise the complex pedagogic skills associated with coaching practices. In adventure sports coaching (ASC), PJDM enables the coach to make best use of his/her skill set by designing, deploying, and refining an optimum blend of teaching strategies that are dependant on the interplay of environmental and interpersonal challenges of the coaching situation. Previous papers have highlighted the importance of PJDM in the planning of programmes, linked sessions, and individual sessions (cf. Nested Thinking; Abraham \& Collins, 2011; Martindale \& Collins, 2010). Notably, however, the dynamic challenge of ASC (including the rapid changes in challenge level against sudden drops in clients' own perceived abilities) adds to the PJDM load with an additional and significant emphasis on in-session thinking (Collins \& Collins, 2013). The extended nature of ASC (whole day activities) results in a series of linked coaching sub-sessions within a whole day journey. These coaching sessions may be discrete or separated by periods of travel between venues, practice en route, or "free time". For example, a sea kayaking coach may conduct a series of related sessions throughout a full day's journey with a thematic link, moving from venue to venue to utilise differing environments.

Of course, this constant auditing and linking process requires a base of knowledge, skills, planning, and philosophical underpinning (Collins, Collins, \& Grecic, 2014) to realise optimal benefits. Consequently, amongst the skills we would logically hypothesise to be present is the ability to respond quickly and efficiently to selected (or preselected) subsets of factors and, of course, "making" the time to reflect. This on-action, in-context reflection forms a critical element of the adventure sports coaches practice and allows the ASC to respond to changes in the environment, in the performers, and in the relationship between the two. A study of how this is 
achieved seems valuable and relevant.

This paper will outline some of the findings from a larger study that has investigated ASC in broader terms. The purpose of this particular paper is to investigate the practical integration of PJDM within applied coaching practices. Specifically, and reflecting the characteristics of effective practice hypothesised above, we focus on how "space" is created and utilised to facilitate individualisation and differentiation in the practical coaching process, whilst also ensuring that the dynamic nature of the environment-person challenge is catered for. To provide a theoretical context to this purpose, this study first considers the nature of the adventure sports coach, the epistemological underpinnings of ASC practice, and the nature of the PJDM process in ASC. Integration of PJDM in practice is then investigated and the results are outlined prior to discussion on the findings and implications in relation to other aspects of research with this study group.

\section{What is the adventure sports coach?}

Collins and Collins (2012) conceptualise ASC as a subgroup of traditional coaching practice and of out- door education. The adventure sports coach shares skills with coaching and educational colleagues, a refined PJDM process, and an identifiably different epistemological framework. The PJDM and epistemology synergise these shared skills. ASC focuses on the individualised development of the skills (motor and cognitive) that enable independent participation in adventure sports. Reflecting the personal construct of adventure, the focus lies in skilful and independent participation rather than high-level performance. Adventure sports coaches have emerged in response to an increased demand that has resulted from an increase in participation.

\section{PJDM epistemological underpinnings}

Collins et al. (2014) recognise the sophisticated epistemology that underpins high- 
level practice in ASC as it does in other domains (cf. Buehl \& Fives, 2009; Hofer, 2002;

Kang, 2008; Thorburn \& Collins, 2003). In the adventure sports environment, the epistemological position is one of recognising and valuing positive adventurous experiences, the need for individualised coaching, and a focus on independent participation as an end goal. In particular, Collins et al. propose that the epistemological chain acts as a framework for an auditing process that characterises the dynamic coaching practice typical in adventure sports. The epistemological chain supports planning, pedagogy, professional development, analysis, and PJDM: this provides the "scaffolding" that underpins the PJDM process which, in turn, synergises the adventure sports coach's practice. It is clear that this scaffolding acts to support the auditing process by which the adventure sports coaches judge the success of their coaching process and also, directly influences the PJDM in action.

Collins and Collins (2013) propose that PJDM is a synergy of two linked decisionmaking processes. They propose that the synergy of both the logical/analytical and intuitive decision-making may, in fact, characterise PJDM in ASC though it seems possible that a synergy of factors would characterise PJDM in that the adventure sports coach will make decisions based on prior experience, a degree of anticipation (drawn from planning and experience), and ongoing learning in that context, all of which occur while anticipating the future impact of current decisions as the environment changes and student development unfolds. This interplay between reflective practice and application is complex in ASC, and will directly inform and be informed by the unfolding coaching process, enabling response to the demands of a dynamic coaching environment. The reflective element may be better considered as on-action in context, recognising that in-action reflection requires momentary time out from the "action present" as Schön (1987) refines his original definitions (Killion 
$\&$ Todenem, 1991; York-Barr et al., 2001). Both the need for a pause and the congestion are conditions that are clearly recognisable in ASC and begs the question how is PJDM and its associated reflective practice integrated into the practical coaching process?

Given the high PJDM load in ASC, this paper investigates how PJDM is physically integrated into the coaching process of high-level adventure sports coaches. Specifically, we consider how time is created for on-action, in-context reflective practice and how opportunities are optimised in the dynamic environments that characterise adventure sports.

\section{Method}

As stated, this paper outlines the findings from a larger study. The thematic analysis provides an in- depth investigation of the themes that occur and reoccur throughout the PJDM over a series of sessions. In this case, the "dynamic processes" are explored by combining semi-structured interviews with video footage relating to real coaching sessions delivered by the participants (Lyle, 2003; Muir \& Beswick, 2007; Rosenstein, 2002). The video was used to stimulate the interview process and deepen the content and richness of the resultant data (cf. Cohen \& Manion, 1994).

\section{Participants}

Data sources included interviews with five expert British adventure sports coaches $\left(M_{\text {age }}=50.3, s=9.1\right)$, together with video and semi-structured interviews relating to 10 ( 2 per participating coach) non-related sessions of ASC practice. Inclusion criteria included: (a) holding multiple British Canoe Union (BCU) Coach Level 5 awards and/or national coaching roles; (b) actively engaged in ASC activity; (c) active as an adventure sports coach educator; (d) willing to unpack and reflect on their own coaching practice; (e) well regarded by peers; (f) holding a coaching qualification in 
at least one other adventure sports and; (g) availability. No incentive was offered and specific demographic information has been withheld to protect anonymity. Purposive sampling was used to ensure a seniority, experience, and inherent quality (at least of selfreflection) in the participants in order to generate a picture of high-level performance. Thus, the participating coaches had a combined 157 years of ASC experience in white water kayaking, sea kayaking, surf kayaking, canoeing, mountaineering, rock climbing, mountain biking, telemark, and alpine skiing; the coaches enjoyed high-status reputations within the field and were all active as participants in adventure sports and coach educations. In the absence of more effective or objective markers (Nash, Martindale, Collins, \& Martindale, 2012), we were confident that this sample presented a picture of good practice.

The primary investigator is a 46 -year old male and has 25 years of experience as an adventure sports coach within the National Centres in the UK. He was a coach educator for the BCU and holds the BCU's Level 5 Coach award in four disciplines, in addition to being a qualified mountaineering and ski instructor. Reflecting these characteristics, the researcher had a good rapport with the participating coaches.

\section{Procedure}

The investigation followed a 4-stage process in which a pre-project, semistructured interview was completed to gain data on the overall philosophy and epistemology of each participant coach. Subsequent pre-session, semi-structured interviews, observation, video of two real non-related sessions, and post-session interviews generated a videotext for each session. Interview guides were constructed and piloted with three similarly qualified coaches and were adjusted before use (Tables I-III). The guides were used to scaffold the interview process; however, depending on 
the breadth and depth of answers provided, they were not always utilised and questions were not always asked verbatim. This approach allowed emergent themes to be explored, revisited, and reconsidered. The empathetic, openly structured interviews varied in length $\left(M_{\text {duration }}=56 \mathrm{~min}\right)$ after initial briefing and orientation questions; interviews were held in a location and at a time agreed with the participants, digitally recorded and transcribed using a commercial transcription service. Sessions were video recorded using a discrete digital chest mounted camera (a Hero 2HD by GoPro Inc.), one worn by the participating coach and a second by the primary researcher during the session.

\section{Data analysis}

The videotexts were read several times and reviewed in line with procedures suggested by Aronson (1994), Braun and Clarke (2006), and Fereday and MuirCochrane (2006). Firstly, the videotexts were read and corrected while listening to the original digital recording in order to be able to imagine the voice of the participants in later reads and to assist in a more "complete analysis" (Smith, Flowers, \& Larkin, 2012, p. 82). During subsequent readings, these videotexts were reconsidered in terms of common, recurring, and underlying themes. As primary themes and initial themes (Miles \& Huberman, 1994) emerged, they were grouped and categorised as appropriate. All coded data were then reviewed; relationships were identified and a thematic map was generated (Crabtree \& Miller, 1999). The thematic map was subsequently reviewed to identify internal and externally coherent patterns of themes. From this thematic map, the themes were further defined and refined. The thematic analysis method adopted in this study was a hybrid of approaches, incorporating an 
inductive, data-driven method (Boyatzis, 1998) and the use of themes (Crabtree \& Miller, 1999). The relationship of findings in this study and those outlined in Collins et al. were considered throughout the discussion.

To enhance the study's trustworthiness, bracketing was utilised (Morrow, 2005). A reflective and reflexive commentary throughout the process, bracketing personal experiences and considering the influence of personal values during the interviews and analysis (Smith, 2011), was maintained. The bracketing process enables the "essence of an experiential structure to be intuitively grasped and isolated" (Loland, 2007, p. 107). Furthermore, this systemic reflection enables the researchers to "bring to light... hidden meanings and qualities" (Loland, 2007, p. 107) and resulted in the focusing and refocusing of the semi-structured interview in response to the participants' contributions. This resulted in the focusing of the semi-structured interview in response to the participants' responses and greater exploration of the participants' reasoning within both interviews. The triangulation of data from interviews and video further enhanced the credibility of the study (Morrow, 2005).

External and internal member checking was also utilised post-analysis to guard against misinterpretation and researcher subjectivity, and to increase credibility (Morrow, 2005). Two independent investigators, an academic colleague and a practitioner colleague within the same faculty, served as external auditors and provided feedback from related but differing perspectives. The participating coaches were also provided internal checks (Sparkes, 1998). In cases where this step identified a disagreement between members of the research team, each investigator reread the original transcript, discussed the coding, and a consensus was reached.

\section{Results}


Initial analysis identified 87 individual primary themes and 27 codified units. The units were subsequently grouped into 16 themes. These were collated into 3 lower order themes and then combined into 2 higher order themes. These have been presented as a hierarchical network in Table IV and subsequently represented in a thematic map presented in Figure 1. This study utilised two super-ordinate themes of creating opportunities for, and utilising gaps in, the coaching process for PJDM. The higher order themes were then considered in the context of the super-ordinate themes. In line with Braun and Clarke (2006), we have provided examples of the themes from the data samples and have varied the length of quotes to demonstrate the depth and richness found in the data

\section{Discussion}

Each coach placed the student at the centre of the coaching process and had a clear epistemological belief that manifested itself in a learner and learning focus to the pedagogic approach. Coach 2 stated "I was quite willing to simply try to work with six individuals rather than one group" with a clear long-term aim to generate a skilful and independent performance. This resulted in the coaches clear long-term aim to generate a skilful and independent performance. This resulted in the coach operating multiple individualised sessions within the larger sessions. Consequently, this causes a larger PJDM load on the coach than may have been originally conceived. This "span of control" acts to apply a further factor that had not previously been anticipated in PJDM. Several of the coaches used the analogy of "juggling" (Coaches 1 and 4) to describe the management of each individual within their group, specifically addressing the need to keep multiple performers (balls) active simultaneously. 
Does the adventure sports coach "create space" for PJDM in the coaching process?

The adventure sports coaches in this study both created and seized impromptu opportunities to make decisions as they arose in the session. Anticipated and planned changes (e.g. tidal condition changes) and behaviour at the venues (e.g. fatigue levels amongst the group) allowed opportunities to be maximised. A deliberate blend of pedagogic strategies (e.g. reciprocal and collaborative), practical structure of activity and practice (e.g. problem-based teaching), and varied practice structures (adapting organismic, environmental, and task constraints) allowed space to be created in the session to such an extent that at times the adventure sports coach appeared to be doing nothing practically though was clearly cognitively highly engaged. This generation of space allowed the differentiation and individualisation of practice because it enabled the PJDM process. The adventure sports coach's intention to differentiate practice in recognition of the value, need, and intention to individualise clearly stems from the philosophical position and placed an additional cognitive load on the coach by multiplying the number of coaching interactions within the group. The adventure sports coach created time to make professional judgments and decisions and individualise the coaching process.

\section{How is the PJDM process integrated into the coaching process?}

In this respect, the epistemological chain and PJDM have to be practically integrated into the applied coaching process.

\section{Managing the span of control.}

Span of control is commonly utilised to describe the number of subordinates that a supervisor manages (Davis, 1951; Gulick \& Urwick, 1937; Jaques, 1988; Koontz, 
1966; Van Fleet, 1974). Although considered in terms of business management, it is likely that span of control was first recognised in command and control of military personnel (Pierce, 1991). The notion of span of control has decreased in significance in business management due to changing business practices; notably, there are less hierarchical management structures. However, span of control remains significant within organisations adhering to hierarchical command and control structures, such as the military and emergency services.

The relevance of span of control for the adventure sports coach could primarily be a risk management rather than a pedagogic function, and may be better described as a span of responsibility in this respect. However, considering the adventure sports coach's related roles in personal development and experience development (Collins \& Collins, 2012), the span of control requires specific management. This need for management is further complicated by the epistemological belief and chain (as identified by Collins et al., 2014) to individualise the coaching practice. The hierarchical structure that necessitates a particular span of control in leadership situations (experience development) is directly at odds with the desire to develop the individual's skilful independent performance (performance and personal development). A combination of the risky, time pressured, and developmental context of the adventure sports coach suggests a synergetic relationship. The continually changing environment and role that characterises the ASC context required the adventure sports coach to manage the span of control. In turn, the span of control varies in each context and appears dependant on the relationship between risk and ability of the students, the aim of the session, and the capacity of the adventure sports coach. 
Within an ASC context, possible factors that affect span of control include the venue in relation to the task and environment. Widely dispersed activities, such as coaching on the sea, working in canoes, or steep creeks in kayaks with small eddies present challenges to the practitioner. Coach 4 explains:

That wasn't appropriate with them because they were at the stage where they needed me to give them technical input, so sending them away for a much longer distance wouldn't have been have been right. Also the environment, if I'd made it any longer [the session], they would've come out of the shelter and into the wind, which would be group management [span of control safety] problems then my concentration would be there [safety and supervision] rather than what I was attempting to do [coaching].

This highlights the challenges an adventure sports coach may encounter in supervising each craft and its paddler(s) in the environment. Namely, if the paddler is highly capable in that environment, he or she may not need supervision to ensure his or her safety, but may benefit from being coached "at a distance".

Adaptability, experience, and capacity of the adventure sports coaches are equally significant; a good understanding of the environment, the students, the task, and the relationship of the three is a critical skill. If the entire group is undertaking the same task, a large span of control could be utilised, this span of control could be reduced by forming subgroups that work on a specific task in each group. This allows some differentiation to students with greater individual demands. These demand may, for example, be due to the impact of the environment on the individual, the stage of learning of that particular skill, fatigue, or other factors. One such strategy utilised in a 
tandem canoe session coaching was the use of collaborative and reciprocal pedagogic approaches (Mosston \& Ashworth, 2002). Coach 1 employed a reciprocal style during a white- water kayaking session with the specific aim to create time. Commenting on the failure of a reciprocal approach, Coach 1 stated:

...perhaps a little bit, if that, went on [referring to potential for peer coaching] not to the degree that I want[ed], but that freed up my time to watch other people and things, so I could leave those two for a wee bit, and ...it's just a way of buying some time.

Observed in sessions, Coaches 2 and 4 utilised semi routine practices to narrow the span of control. The coach may have a range of teaching practices and exercises to enhance a particular skill; in this example, however, the environment was very controlled. In some approaches, each individual may be using a different exercise that is selected from a known set of regularly used options; this reduces the need for the coach to generate and innovate new solutions to the challenges presented by all individuals in the group. However, the use of "tried and tested" favourites may actually allow generation of unique solutions to novel problems. In this respect, attention can be focused on the unique challenges of a particular individual in a particular context.

These approaches act to reduce the volume of coaching tasks but, in reality, do not lighten the load. Other decisions related to the changing context (anticipated and actual) and logistics must also be factored into the span of control. For example, weather and tidal changes, learner's development, and time keeping all impact the adventure sports coach's span of control. In this respect, the adventure sports coach seems aware of his or her individual capacity in given environments and manages the 
span of control, knowing what to do in "big environments" (as stated by Coach 4).

Thus, knowing how and why to manage the span of control represents a meta-decision.

Span of control application in hierarchical systems, namely a clear superior and subordinate structure, has survived the test of time. However, adventure sports coaches working to generate a performance that is independent will not be seeking to create, implicitly, or explicitly that up and down structure. We propose that the horizontal integration is essential to generating a performance that is independent of the linear hierarchy. In this respect, the adventure sports coach acts to facilitate a shared mental model within that micro community of practice. In an adventure sports context, decision-making is not a single linear process (Collins \& Collins, 2013); the aforementioned shift of cognitive load necessitates the development of concise links "across" the process and a reduction in dependence on the links "up and down". This shift towards generating an independent performance via a student-centred pedagogic approach (Collins et al., 2014) is facilitated by the active generation of these horizontal connections. These horizontal integrations are generated via the use of self-gauging, reciprocal, problem-based teaching, collaborative pedagogic approaches, and comparative teaching strategies (Mosston \& Ashworth, 2002). The horizontal integration concept enables the adventure sports coach to manage the span of control in response to the context and desired level of independence during the practice.

\section{Pedagogic strategies.}

The pedagogic strategies reflected the epistemological chain and had a clear focus on student independence, "learnacy" (Claxton, 2002), and a reduction of coach dependency. Again reflecting the carefully selected physical environment, the 
adventure sports coach employed a range of strategies that managed arousal levels, information overload, and presentation of information relevant to the environment, task, or person.

Several adventure sports coaches allowed students to leave "formal teaching sessions" once they felt they had sufficient information to attempt the task. This allowed the student to limit potential overloads and also created a natural stagger in the activity, with some student leaving the "formal teaching" earlier than others. Coach 2 articulated the process "I introduced what we're going to do next and I invited them to stick around if they wanted to look at it a bit more" and observed from the video that "So people had gone off when they felt they were ready to." This was mirrored by the adventure sports coaches who ensured students had the opportunities for questioning prior to practice, during practice, and post-practice, again staggering the activity.

The potential for several students to return for feedback simultaneously remained and the adventure sports coach also refined his or her feedback methods to be concise and effective. At times, this efficiency was achieved by creating a personalised, intrinsic feedback mechanism, and additional extrinsic mechanisms to allow the student to gauge his or her own performance. This feedback mechanism, in turn, allowed the use of comparative exercise routines and collaborative and reciprocal approaches, which reduced the span of control required by the adventure sports coach. At other times, nonspecific feedback methods (e.g. a thumbs up, Coach 1) were used to act as a "stop gaps" prior to encouraging more activity. "Conscious ignoring" (Coach 3), in which no contact with the student was made, was also used as a deliberate tactical choice on the coach's part to reduce dependence on feedback from the coach and encourage greater 
independent activity.

Practical structure. Provision of feedback was managed by physical management of the venue to naturally stagger performer involvement with the coach. Circuits, in which the students passed the coach, in turn, allowed greater observation of the individual. Feedback delivery was tailored on a 1:1 basis. This individualised feedback was at times facilitated by physical movement by the coach around the venue, seeking out students for feedback, or moving away from students to avoid feedback (conscious ignoring, Coach 3 identified earlier). This physical positioning enabled feedback to be provided to one student, while observing another for either coaching or safety purposes. Coach 5 commented following a white- water kayak session: "I position myself and I suppose, more so with the other two [students] so the interaction can be shorter.... So the questions can be more directive." The choice of approach is driven by two factors: the need for observation from a different perspective and the timing and frequency of feedback identified for a particular student. Movement around the venue was also used to create variation in practice without explicitly resetting the task, reduce frequency of feedback, and bandwidth the feedback. As an example, Coach 3 moved position to ensure that the exercise set was practised in different conditions and performed up wind, down wind, and on a beam wind by changing position and calling students to him for feedback from the different positions as the performance altered.

Practice was frequently structured to enable several performances or related tasks, comparing and contrasting different adaptations in different conditions. Coach 2 commented: "I would typically get them [the students] to go and experiment with the elements of their technique" and indicated that this created a stagger in the session and 
differentiated sessions “...they were approaching the session in slightly different ways according to the regularity which they came back to me and the answers they gave to me." As an example, Coach 2 commented on the impact on an individual in the observed session: "It absorbed him for a fair amount of time and he seemed to be quite happy." During this time, direct observation of the video footage highlighted an extended interaction with another member of the group. These tasks were also set with an open-ended manner (i.e. when a particular level of performance or cognitive task

had been achieved the goal could be altered). The coach encouraged the development of (via questioning and problem based learning approaches) and encouraged intrinsic feedback mechanisms (via rating scales or use of observational flags and markers) to help facilitate independent reflective practice by the student. These intrinsic and extrinsic feedback mechanisms also enabled efficient communication between student and coach.

\section{Conclusion and generic implications}

The underpinning epistemological chain identified by Collins et al. (2014) helped to identify the philosophical positions of the adventure sports coaches in this study. One element of the epistemological chain had a direct impact on the adventure sports coaches practical behaviour in the field, namely to develop a skilful, independent individual performer. This epistemological stance is characteristic of all high-level coaching practice. Significant in this process was the shift in cognitive load during development, from the coach to the individual performer. As stated, coaching each member of the class as an individual and differentiating the pedagogic relationship initially increases the cognitive load on the coach. This may be impossible to manage 
when the interaction between ability of the group of individuals and the nature of the environment proves too risky, as is often the case in ASC. However, the dynamic nature of the coaching environment is also common across sports and, therefore, we suggest that all coaches will require the skills to facilitate the individualisation if desired. Effectively, the environment is acting as a component in span of control management.

Specific to ASC, careful and initially conservative selection of venue and, with it, the extent of the adventure characterise early sessions until rapport is established between the adventure sports coach and the student. Common to all coaching, once rapport is established, further individualisation and differentiation can be integrated into the process. The coaches in this study employed a range of observable and definable strategies to manage the pedagogic interaction, the span of control, practical session structure, and the use of the time available. These strategies have application in all coaching practice.

The selection of venues and activities to create a natural stagger of performer involvement was supplemented by movement around the venue by the coach; multifunction positioning enabled simultaneous feedback and observation of others in the activity to monitor safety whilst allowing and encouraging "constant" practice.

Removing people from activity as the coach identified a need for feedback was another key tool. Other methods included allowing the individual to break from practice to seek or generate further input, plus the use of linked exercises in different orders for different students, thus reducing the "what next factor" and generating the variety in practice required for the independent skilful performance desired. In turn, this provides 
an easy next step for the student and a lower PJDM load. Allowing performers to leave "group teaching sessions" once they feel they have sufficient information to attempt the task generates a natural stagger in the process and allows the student to gauge potential overload and manage his or her own learning. Ensuring performers have opportunities for questioning prior to, during, and "post- practice" also generates natural staggers in activity and manages the cognitive load. Use of reciprocal, collaborative, problembased and comparative teaching approaches to generate "horizontal integration" and management of the span of control narrows the span of control. Encouraging and developing the student's own reflective practice develops "learnacy" (Claxton, 2002) and also reduces direct contact with the coach. This, in turn, encourages independence of performance. This is facilitated with the development of intrinsic, extrinsic, and augmented feedback mechanisms. Efficient feedback reduces the time spent in delivering feedback (i.e. tailored, accurate, and concise).

The coach generates dendritic links throughout the coach-student interactions. This serves to man- age the span of control, developing independent performance, and encourage robust performances. This, in turn, raises an important aspect of coach to student ratios; the tendency in ASC is to reduce the staff to student ratio, the more challenging the environment or to assume that individualised coaching can only be achieved in very low student to coach ratios. The strategies outlined above enable any coach to manage a larger group while differentiating the coaching. In ASC, the decision may be better considered as the relationship between student ability and the environment. This would have a direct impact on the field of guiding (experience development) if compared with performance and personal development. The later cases 
where development is the priority potentially require a narrower span of control.

Individualised coaching practices place a high cognitive load on any coach. The high-level adventure sports coach also manages the impact of the environment on performance and potential development as part of that differentiated practice. The span of control reflects the capacity of the coach, risks associated with the immediate environment, and individual learner short-, mid-, and long-term needs. The adventure sports coach utilises a range of strategies that enables to movement around the environment, directly manage interactions with the individual students, and balance the risks with the benefits of the coaching process. These strategies and results offer positive lessons for generic and adventure sports- specific coach education. 


\section{References}

Abraham, A., \& Collins, D. (2011). Taking the next step: Ways forward for coaching science. Quest, 63(4), 366-384.

Aronson, J. (1994). A pragmatic view of thematic analysis. The Qualitative Report, 2(1), 1-3.

Boyatzis, R. E. (1998). Transforming qualitative information: Thematic analysis and code development. Thousand Oaks, CA: Sage.

Braun, V., \& Clarke, V. (2006). Using thematic analysis in psy- chology. Qualitative Research in Psychology, 3(2), 77-101.

Buehl, M., \& Fives, H. (2009). Exploring teachers' beliefs about teaching knowledge: Where does it come from? Does it change? The Journal of Experimental Education, 77, 367-408.

Claxton, G. (2002). Building learning power: Helping young people become better leaders. Bristol: TLO.

Cleermans, A., \& Jimenez, L. (2002). Implicit learning and con- sciousness: A graded, dynamical perspective. In R. M. French \& A. Cleeremans (Eds.), Implicit learning and consciousness: An empirical, philosophical and computational consensus in the making (pp. 1-40). Hove: Psychology Press.

Cohen, L., \& Manion, L. (1994). Research methods in education

(4th ed.). London: Routeledge.

Collins, L., \& Collins, D. (2012). Conceptualizing the adventure- sports coach. Journal 
of Adventure Education and Outdoor Learning, 12(1), 81-93.

Collins, L., \& Collins, D. (2013). Decision-making and risk management in adventure sports coaching. Quest, 65(1), 72-82.

Collins, L., Collins, D., \& Grecic, D. (2014). The epistemological chain in high level adventure sports coaches. Journal of Adventure Education and Outdoor Learning. http://dx.doi.org/ 10.1080/14729679.2014.950592

Court, D. (1988). Reflection-in-action: Some definitional pro- blems. In P. Grimmett \& G. Erikson (Eds.), Reflection in teacher education (pp. 143-146). Vancouver: Pacific Educational Press. Crabtree, B. F., \& Miller, W. L. (1999). Using codes and code manuals: A template organizing style of interpretation. In B. F.

Crabtree \& W. L. Miller (Eds.), Doing qualitative research (2nd ed., pp. 163-177). Newbury Park, CA: Sage.

Davis, R. C. (1951). The fundamentals of top management. New York, NY: Harper.

Evans, J. St. B. T. (2008). Dual processing accounts of reasoning, judgement and social cognition. Annual Review of Psychology, 59, 255-278.

Fereday, J., \& Muir-Cochrane, E. (2006). Demonstrating rigor using thematic analysis: A hybrid approach of inductive and deductive coding and theme development. International Journal of Qualitative Methods, 5(1), 80-92. Retrieved from http://www. ualberta.ca/ iiqm/backissues/5 $1 / \mathrm{html} /$ fereday.htm

Gulick, L., \& Urwick, L. (Eds.). (1937). Papers on the science of administration. New York, NY: Institute of Public Administration. 
Hofer, B. K. (2002). Epistemological worldviews of teachers: From beliefs to practice. Issues in Education, 8, 167-174.

Jaques, E. (1988). Requisite organisation: A total system for effective managerial organization and managerial leadership for the 21 st century. Arlington, VA: Cason Hall

Kang, N. (2008). Learning to teach science: Personal epistemol- ogies, teaching goals, and practices of teaching. Teaching \& Teacher Education, 24, 478-498.

Killion, J., \& Todenem, G. (1991). A process of personal theory building. Educational Leadership, 48(6), 14-16.

Koontz, H. (1966). Making theory operational: The span of man- agement. Journal of Management Studies, 3, 229-243.

Loland, S. (2007). Outline of a phenomenology of snowboarding. In M. McNamee (Ed.), Philosophy, risk and adventure sports. London: Routledge, Taylor \& Francis.

Lyle, J. (2003). Stimulated recall: A report on its use in naturalistic research. British Educational Research Journal, 29(6), 861-878.

Martindale, A., \& Collins, D. (2010). But why does what works work? A response to Fifer, Henschen, Gould, and Ravizza. The Sport Psychologist, 24(1), 113-116. Retrieved from http:// journals.humankinetics.com/

Miles, M. B., \& Huberman, A. M. (1994). Qualitative data ana- lysis (2nd ed.). London: Sage. 
Moon, J. (1999). Reflection in learning and professional development: Theory and practice. London: Routledge.

Morrow, S. L. (2005). Quality and trustworthiness in qualitative research in counseling psychology. Journal of Counseling Psychology, 52(2), 250-260.

Moshman, D. (2000). Diversity in reasoning and rationality: Meta cognitive and developmental considerations. Behavioral and Brain Sciences, 23, 689-690.

Mosston, M., \& Ashworth, S. (2002). Teaching physical education

(5th ed.). San Francisco, CA: Pearson Education.

Muir, T., \& Beswick, K. (2007). Stimulating reflection on prac- tice: Using the supportive classroom reflection process. Mathematics Teacher Education and Development, 8, 74-93. Retrieved from http://www.merga.net.au/node/42

Nash, C., Martindale, R., Collins, D., \& Martindale, A. (2012). Parameterising expertise in coaching: Past, present and future. Journal of Sports Sciences, 30, 985-994.

Pierce, W. G. (1991). Span of control and the operational comman-der: Is it more than just a number? (Monograph). Retrieved from http://www.dtic.mil/dtic/tr/fulltext/u2/a240178.pdf; http://www. nova.edu/ssss/QR/BackIssues/QR2-1/aronson.html

Rosenstein, B. (2002). Video use in social science research and program evaluation. International Journal of Qualitative Methods, 1(3). Retrieved from http://www.ualberta.ca/ ijqm 
Schön, D. (1983). The reflective practitioner: How professionals think in action. Aldershot: Ashgate.

Schön, D. (1987). Educating the reflective practitioner. San Francisco, CA: JosseyBass.

Smith, J. A. (2011). Evaluating the contribution of interpretative phenomenological analysis. Health and Psychology Review, 5(1), 9-27.

Smith, J. A., Flowers, P., \& Larkin, M. (2012). Interpretative phenomenological analysis: Theory, method and research. London: Sage.

Sparkes, A. (1998). Validity in qualitative inquiry and the problem of criteria: Implications for sport psychology. The Sport Psychologist, 12(4), 363-386. Retrieved from http://journals. humankinetics.com/tsp

Thorburn, M., \& Collins, D. (2003). Integrated curriculum mod- els and their effects on teachers' pedagogy practices. European Physical Education Review, 9, 185209.

Van Fleet, D. (1974). Span of control: A review and restatement. Akron Business and Economic Review, 5(4), 34-42.

York-Barr, J., Sommers, W. A., Ghere, G. S., \& Montie, J. (2001). Reflective practice to improve schools: An action guide for educators. Thousand Oaks, CA: Corwin. 


\section{Table 1}

Adventure sports coach pre-event interview, relationship and rapport building with observed.

\begin{tabular}{|c|c|c|}
\hline QUESTION & PROBE & $\begin{array}{l}\text { AIM - WHAT ARE WE } \\
\text { INTERESTED IN }\end{array}$ \\
\hline \multicolumn{3}{|l|}{ Administration } \\
\hline $\begin{array}{l}\text { Have I received........ } \\
\text { Do you have any } \\
\text { questions regarding the } \\
\text { study or the process of } \\
\text { the study? } \\
\text { Have you been busy } \\
\text { recently? }\end{array}$ & $\begin{array}{l}\text { Signed consent. } \\
\text { CV } \\
\text { Currency, Level of activity }\end{array}$ & $\begin{array}{l}\text { Admin } \\
\text { Rapport building } \\
\text { Outline } \\
\text { Questions } \\
\text { Context (buy in) } \\
\text { This can be throw away } \\
\text { stuff! (Get use to } \\
\text { Dictaphone) } \\
\text { Break in for ALL } \\
\text { interviews }\end{array}$ \\
\hline \multicolumn{3}{|l|}{ Background } \\
\hline $\begin{array}{l}\text { What do you feel are your } \\
\text { key qualifications and } \\
\text { experiences that relate to } \\
\text { your practice? } \\
\text {... what makes you an } \\
\text { expert?... } \\
\text {.... what makes you a } \\
\text { professional adventure } \\
\text { sports coach?... } \\
\text { What are the challenges } \\
\text { of your work? }\end{array}$ & $\begin{array}{l}\text { Experience } \\
\text { Education Background } \\
\text { Training / CPD Learning } \\
\text { Sources of knowledge } \\
\text { Observation } \\
\text { Questioning, Listening } \\
\text { Information provided } \\
\text { Injury } \\
\text { Time management, } \\
\text { Logistics } \\
\text { Conditions } \\
\text { Professionalism }\end{array}$ & $\begin{array}{l}\text { What the ASC feels are } \\
\text { important skills and } \\
\text { attributes for them to } \\
\text { have? }\end{array}$ \\
\hline Philosophy & & \\
\hline $\begin{array}{l}\text { Why do you coach } \\
\text { adventure sports? } \\
\text { What is your overall aim/ } \\
\text { aims for your coaching } \\
\text { practice? }\end{array}$ & $\begin{array}{l}\text { Philosophy } \\
\text { Influences } \\
\text { Sources of knowledge } \\
\text { Ethics } \\
\text { Professionalism }\end{array}$ & $\begin{array}{l}\text { What are the coach's, } \\
\text { aim and objectives? } \\
\text { What factors shaped } \\
\text { these? }\end{array}$ \\
\hline $\begin{array}{l}\text { What factors have } \\
\text { influenced your } \\
\text { approaches to coaching? } \\
\text {.... what are the greatest } \\
\text { influences?.... }\end{array}$ & & \\
\hline
\end{tabular}


Table 2

Second stage interview- Adventure sports coach pre-event interview, QUESTION

PROBE

Objectives

Who are we 'working' with?

What do you know about this group?

The Session Plan/Plans

What kind of planning have you done for this session?

What factors have you included in your plan?..........Why?...

How have you decided to focus the session? ........Why?....

How has this been incorporated into you planning?

Size of group, gender
Experience
Aims objectives
Ability
Motivations
Depth of 'knowledge
'gleaned' from group
Observation, Questioning,
Booking details
Individual's within group

Flexibility Adaptability

Focus

Factors in plan

Environment Conditions/

Location

Individuals v's Group

Equipment \& Logistics

Experience

Training / CPD

Learning Environmnet

Reflection

When did planning happen

Extent of Plan

\section{AIM-WHAT ARE WE}

INTERESTED IN

How much detail on the individuals?

How much based on experience

How much based on assumption?

How in information gathered in ASC?

\section{The PJDM Process in Pre-planning}

What factors affect how you made your judgments and decisions regarding the plan?

What effects do you anticipate your pre -planning and PJDM will have in the session?
Understanding of DM

Adaptation

Learning from... Reflection

Intuition / Experience

Psychological/ Behavioural development

Performance development

Other support

Awareness of different agendas

Awareness of complexity - needs

analysis

Contact time

Location/ Conditions

Experience of students

Personality

Student Goals

Safety

Logistics

Short, mid long term goals
What is the coach's main area in which they make PJDM Its their a focus or priority in this PJDM? Does this relate to session aims and objectives What factors does the coach place value on? How do they arrive at that prioritisation? What external factors affect the DM methods used? Is there a flexible approach? 
Table 3

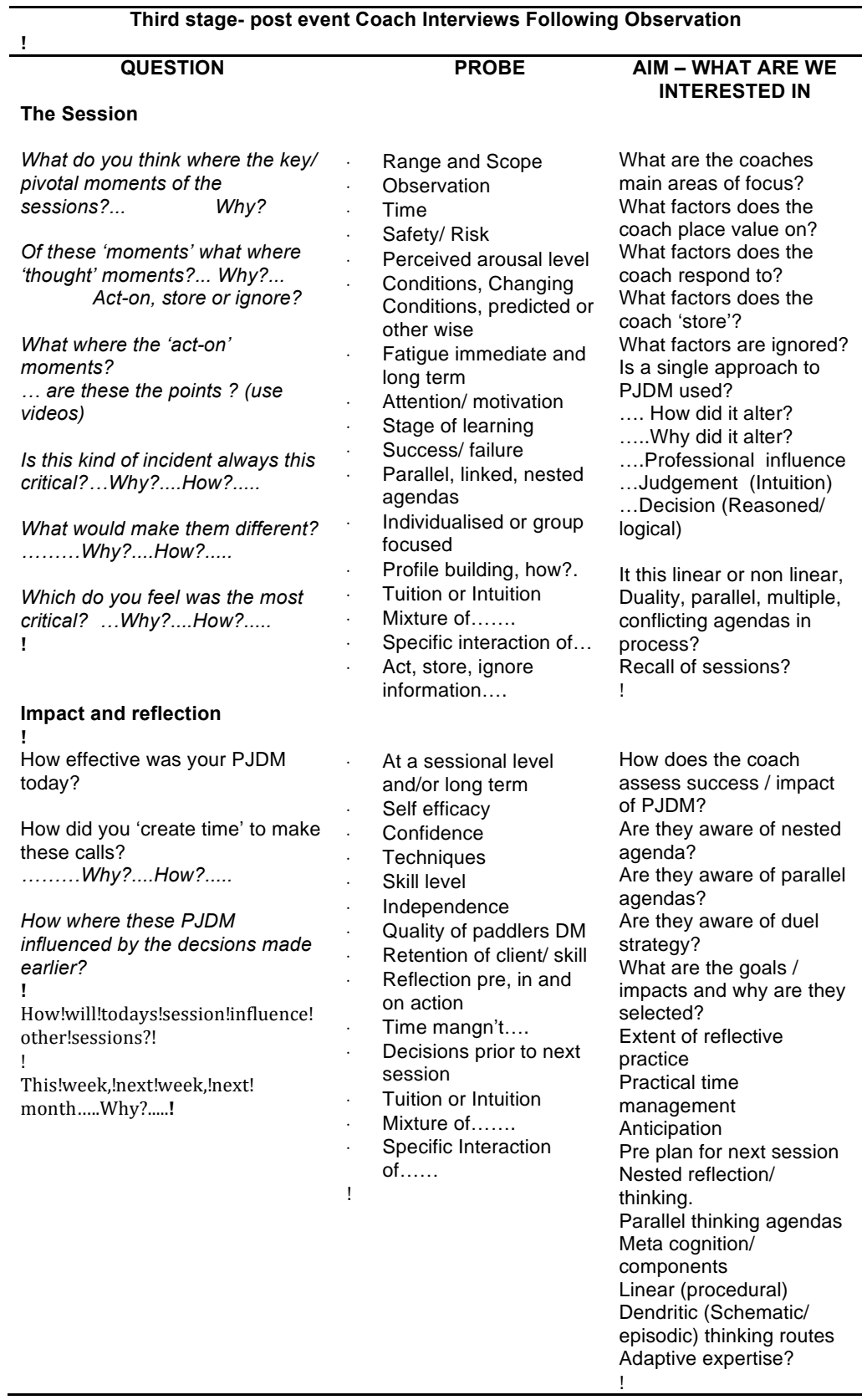


Table 4

Table IV. Thematic analysis of interviews.

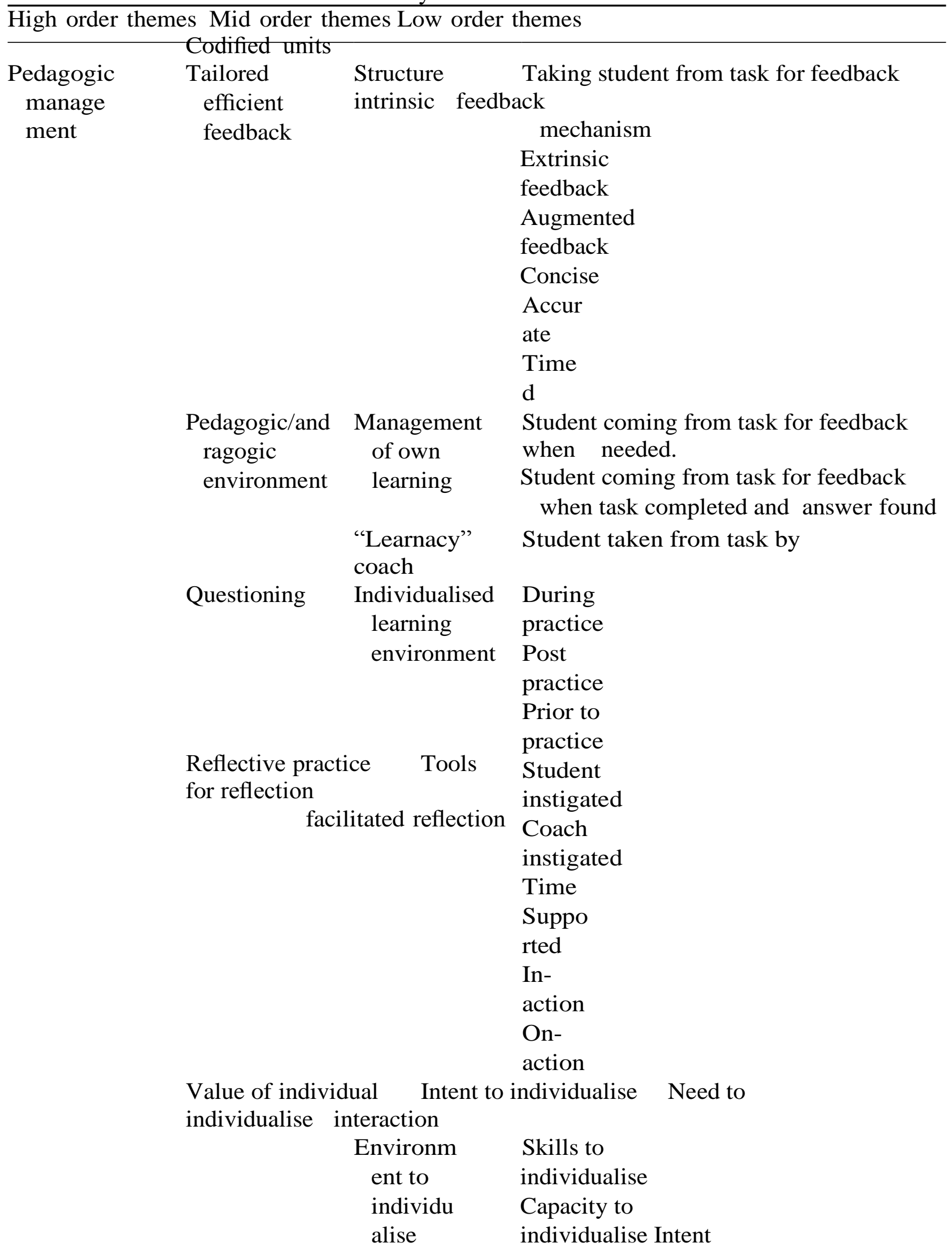


to individualise

Risk vs. ability Ability of student Risk perception

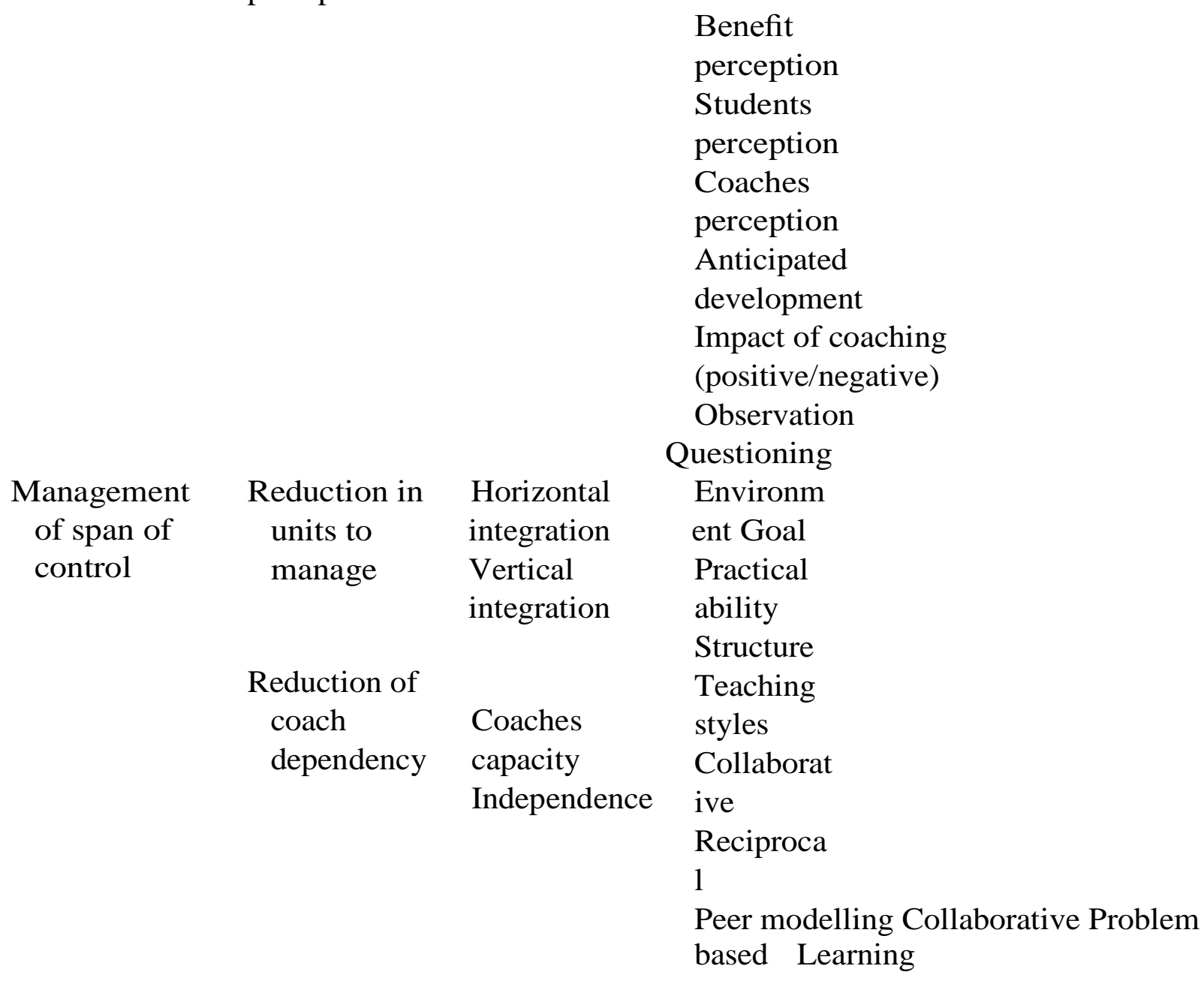


Time management

Venue

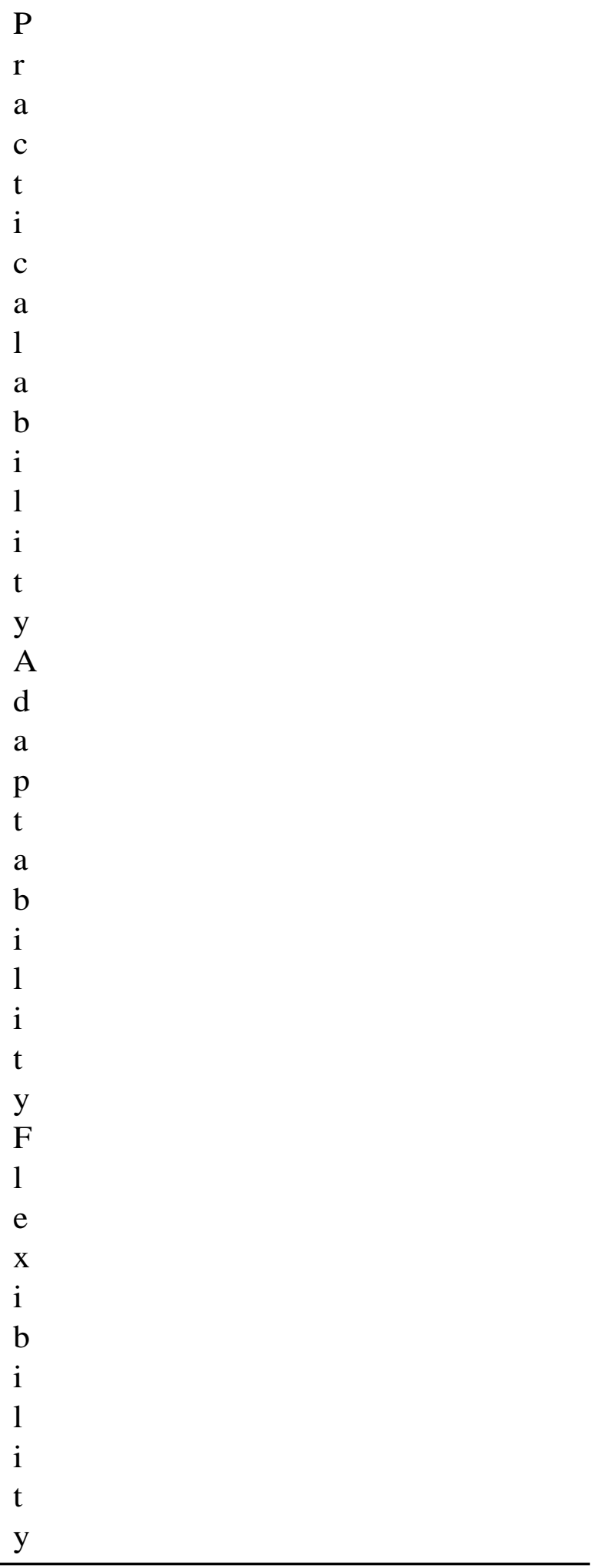

